\title{
What Is the Driving Force behind Consolidations in the Insurance Market? ${ }^{+}$
}

\author{
Mahito Okura \\ Associate Professor, Faculty of Economics, Nagasaki University \\ Address: 4-2-1 Katafuchi, Nagasaki-city, Nagasaki 850-8506, JAPAN \\ Email: okura@nagasaki-u.ac.jp. \\ Noriyoshi Yanase \\ Associate Professor, Faculty of Business Administration, Tokyo Keizai University \\ Address: 1-7-34 Minami-cho, Kokubunji-city, Tokyo 185-8502, JAPAN \\ Email: yanase@tku.ac.jp.
}

\begin{abstract}
Purpose:
The purpose of this study is to discuss whether insurers could have a strong motivation for M\&A for the future because they need to survive within the industry under the oversaturated market.

Recently, Japanese non-life insurance market, mainly the automobile insurance market, has reached the point of saturation in recent years due to the oversaturated domestic automobile market. At that time, the industry has also experienced successive large-scale M\&A transactions.
\end{abstract}

\section{Design/methodologylapproach:}

Using a theoretical model developed by Salent el al. (1983), we discuss whether an insurer's motivation for M\&A could be affected by a saturation of the market. We also clarify whether insurance premium deregulation is a necessary condition for merger incentives.

\section{Findings:}

Our conclusion is as follows. First, necessary requirement for insurers' motivation of consolidations is to loosen the rate regulation, and second, the sufficient condition is saturation of market.

\section{Research limitations/implications:}

This result is intuitive to understand recent circumstance surrounding Japanese nonlife insurance industry.

\section{Originality/value:}

As far as we know, this study is the first paper to discuss the relationship between a potential market size and $M \& A$ transactions.

\section{Keywords:}

Consolidations, Deregulation, Insurance Market

\section{Paper type:}

Research Paper

\footnotetext{
+ The authors thank session participants at the 2011 Asia Pacific Risk and Insurance Association Annual Meetings.
} 


\section{Introduction}

Over the last couple of decades, nonlife insurance companies have experienced a wave of mergers and acquisitions (hereafter, M\&As) around the world. In the 1990s, a considerable number of insurers in the United States and the EU countries faced a wave of consolidations. The Japanese nonlife insurance industry also experienced large-scale M\&A transactions in the early 21st century. This raises a question: What is the most important driving force for M\&A transactions in the insurance industry? In fact, there are diverse views about the driving force for consolidations in insurance companies. This study discusses how an insurer's motivation could be affected by insurance premium deregulation and market saturation. We conclude that a loose rate regulation is a necessary condition and market saturation a sufficient condition for consolidation in the insurance industry.

In the recent M\&A cases, deregulation seems to be one of the most important driving forces. For example, as we will discuss in more detail later, several major Japanese nonlife insurers were consolidated with each other after a few years of the drastic 1995 amendment to the insurance business law, mainly intended to promote deregulation and competition within the industry. Boubakri et al. (2008) argue that deregulation may have created incentives for US insurers to undertake M\&As in the European market with the emergence of new business opportunities. On the other hand, Cummins and Weiss (2004) point out that deregulation did not play a role in the US property-liability insurance industry. Thus, whether these regulatory developments (deregulation policies) led to the series of M\&A transactions around the world is still a controversial issue ${ }^{1}$.

Even though a great deal of effort has been made on the driving force of M\&A transactions, little attention has been given to whether the saturation of insurance markets could be the driving force. In other words, if an insurance market has reached the point of saturation, insurers could have a strong motivation for M\&A because they need to survive within the industry. Actually, insurers can

\footnotetext{
1 Turning from deregulation issues to other driving forces of M\&A transactions, Cummins and Xie (2008) suggest that the wave of M\&As in the US property-liability insurance industry was driven by changing technologies, particularly advances in computing and communications. Moreover, the economic rationales for these operations include the intention of insurers to increase their geographical reach and product range (Amel et al., 2004) and to benefit from scale and scope economies (Cummins et al., 1999). The insurers could also have initiated these transactions to benefit from financial synergies (Chamberlain and Tennyson, 1998), reduce riskiness, and improve the amount/timing of their cash flow streams (Cummins and Weiss, 2004). Contrary to the above studies, the existing financial literature, however, suggests that M\&A transactions may destroy rather than create value, especially if they are motivated by managerial hubris (Roll, 1986). Managers interested in maximizing the size of their business empires can waste corporate resources by overpaying for acquisitions rather than returning cash to the shareholders. Hence, a negative impact on the bidders' firm value could be observed.
} 
expand their scale of operation by M\&A transactions. As a result of these transactions, they might expect to obtain competitive advantages in terms of economics of scale. Overall, there could be a negative relationship between the potential market size and an insurer's motivation.

Using a theoretical model developed by Salent el al. (1983), we discuss whether an insurer's motivation could be affected by a saturation of the market. We also clarify whether insurance premium deregulation is a necessary condition for merger incentives. As far as we know, this study is the first paper to discuss the relationship between a potential market size and M\&A transactions. The remainder of the paper is organized as follows. Section 2 describes the background of this study: the recent trend of consolidation in the Japanese nonlife insurance industry and the drastic change of the Japanese nonlife insurance business to a saturated market. Section 3 discusses our model and its implications. The final section summarizes our discussion and points out our future challenges.

\section{Recent Developments in the Japanese Market}

Deregulated and Oversaturated insurance market The Japanese nonlife insurance industry has entered a new era, bringing about dramatic changes since the 1995 amendment to the Insurance Business Law ${ }^{2}$. The new law came into force on April 1, 1996. Because the new law is the first major revision in the 56-year history of the insurance business law in Japan, it has had a significant impact on the country's insurance industry, both life and nonlife. The purpose of the new law is to deregulate and promote competition in the insurance market ${ }^{3}$. In fact, although the nonlife insurance industry had to follow strict rate regulation before deregulation, differential-rate automobile insurance was introduced in September 1997 under the deregulation schedule, and some foreign insurers started marketing this type of cover. In July 1998, nonlife insurers were released from the obligation to use premium rates calculated by the official rating organization, the Nonlife Insurance Rating Organization of $\mathrm{Japan}^{4}$. As a result, the industry has entered the age of full-fledged liberalization.

\footnotetext{
2 In fact, the move was touched off by a report submitted in June 1992 by the Insurance Council, an advisory panel to the Finance Minister. On the basis of this report, drastic changes were made to consolidate the three existing laws: the Insurance Business Law, the Law concerning the Control of Insurance Soliciting, and the Law concerning Foreign Insurers.

3 The new law has three basic principles: deregulation, liberalization, and establishing sound management.

${ }^{4}$ The Nonlife Insurance Rating Organization of Japan was established based on the Law concerning Nonlife Insurance Rating Organizations. The objective of this law was to promote the sound development of the general insurance business and to protect policyholders' interests by setting up nonlife insurance rating organizations to ensure appropriate calculations of (1) reference risk premium rates and (2) standard premium rates for the two policy-based insurance schemes, compulsory automobile liability insurance and earthquake
} 
Figure 1 shows the distribution of net premiums across lines of business (LOBs) in 2007, indicating that automobile accounts for the major share.

Figure 1: Distribution of NPW across lines in 2007

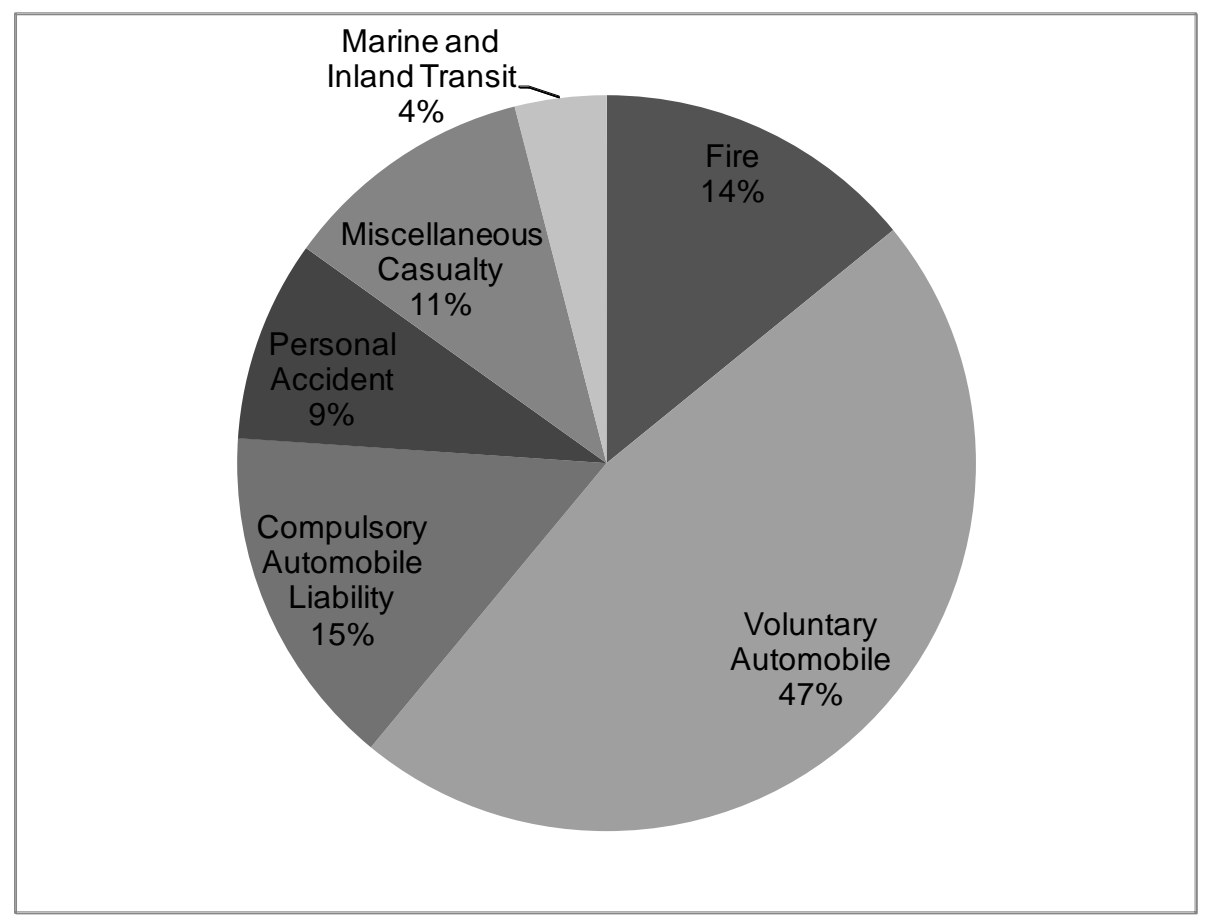

(Source) The Statistics of Japanese Non-life Insurance Business, Insurance Research Institute

Figure 2 shows the net premium income (NPI) of automobile insurance in Japan between 1967 and 2008. The NPI rose to the peak in 1998 and has remained steady around 3,600 billion JPY ever since. Obviously, the automobile insurance market has become saturated.

insurance. 
Figure 2: Net Premium Income of Automobile Insurance in Japan (1967-2008)

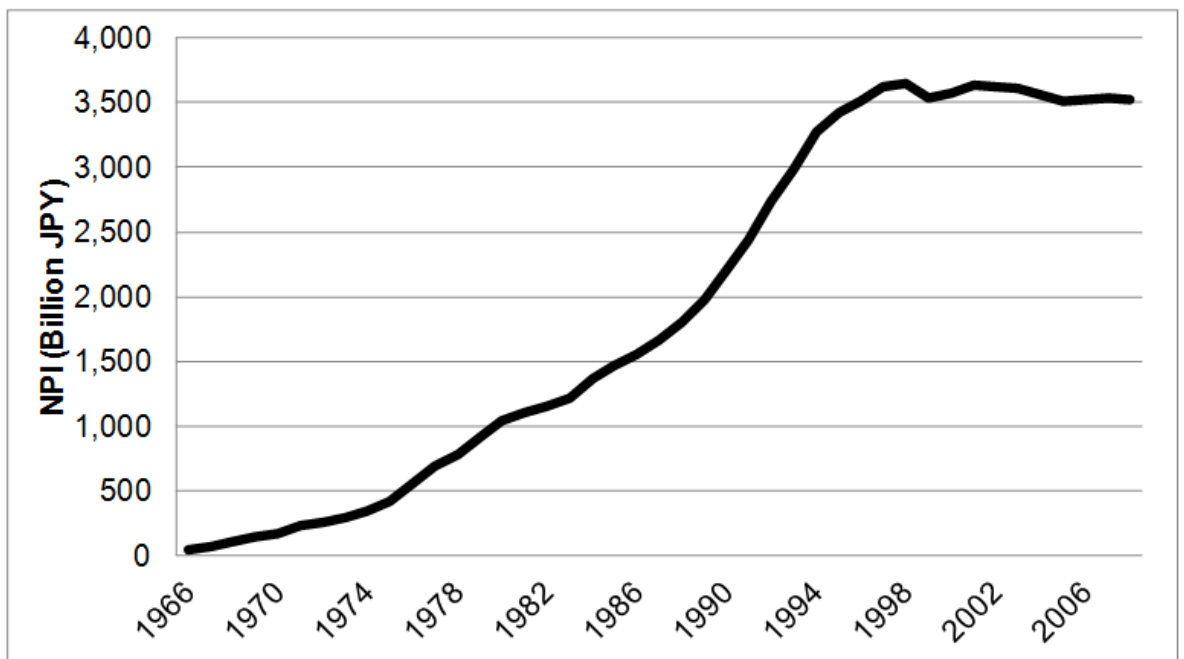

(Source) The Statistics of Japanese Non-life Insurance Business, Insurance Research Institute

Figure 3 indicates how the number of automobiles in Japan has increased (or decreased) compared with the previous year. Recent year-on-year rates are very low, almost $0 \%$, meaning that the domestic demand for automobile has also reached a saturation point.

Figure 3: Year-on-year growth rate of the number of automobiles in Japan (1967-2008)

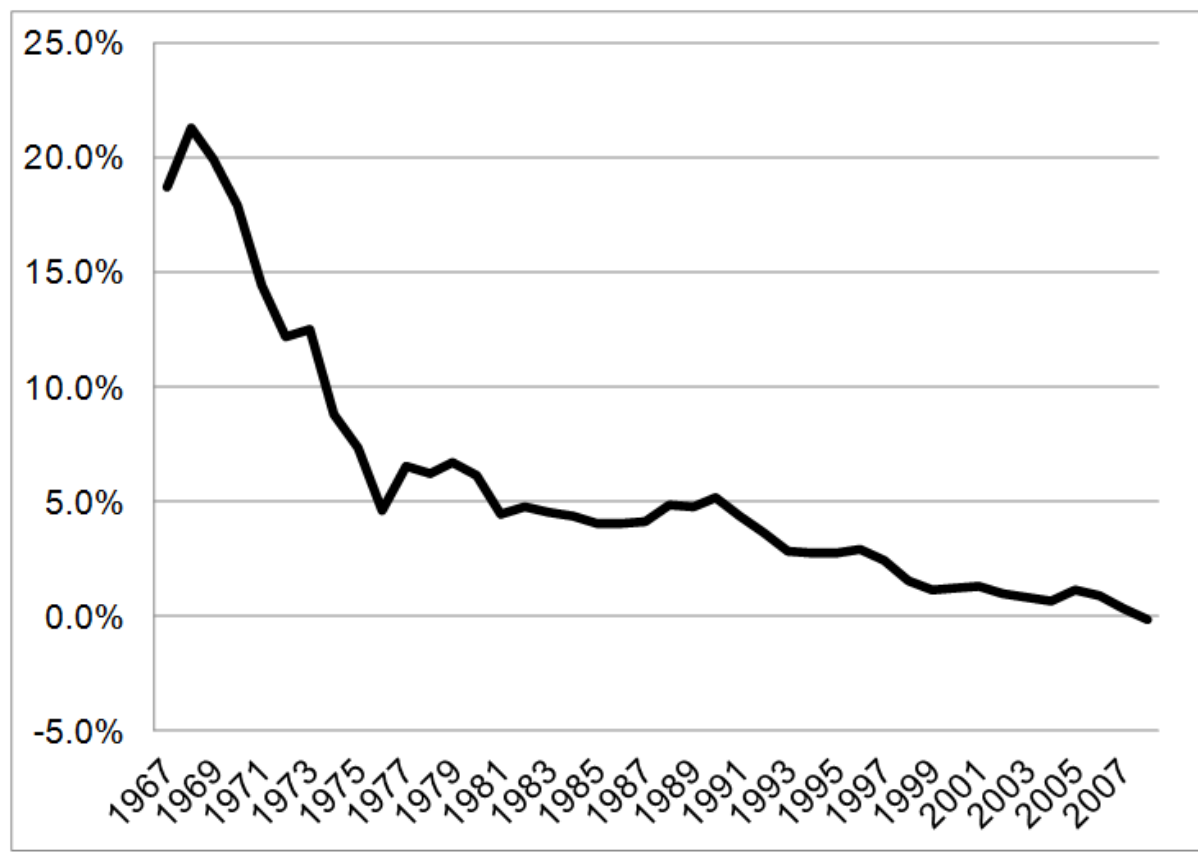

(Source) Automobile Inspection and Registration Information Association 
A Massive Wave of Consolidations A massive wave of consolidations swept through the Japanese nonlife insurance market between 2001 and 2004. Major nonlife insurers announced alliances, integration, and mergers among themselves in the two years following 1999. In 2001, four new nonlife insurers were established through mergers: NIPPON-KOA, AIOI, NISSAY-DOWA, and MITSUI-SUMITOMO ${ }^{5}$. Furthermore, the second largest nonlife insurer, YASUDA, also merged with NISSAN and TAISEI to establish a new company, named SOMPO-JAPAN. In October 2004, the largest nonlife insurer, TOKIO-MARINE, merged with NICHIDO. The new merged company, TOKIO-MARINE-NICHIDO has become a giant straddling the Japanese nonlife insurance industry. Figure 4 shows the changes in market shares between the end of fiscal years 2000 and 2004 . The tremendous impact of the massive wave of consolidations between 2001 and 2004 could be observed.

Figure4: The Change of the Market Shares (Ex-Post the Wave of M\&As)

March 2001

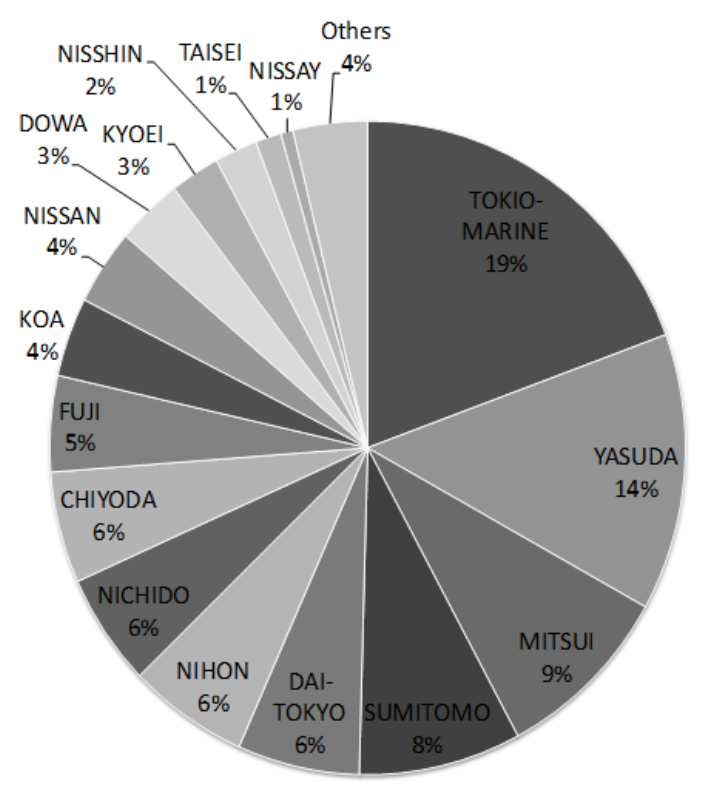

March 2005

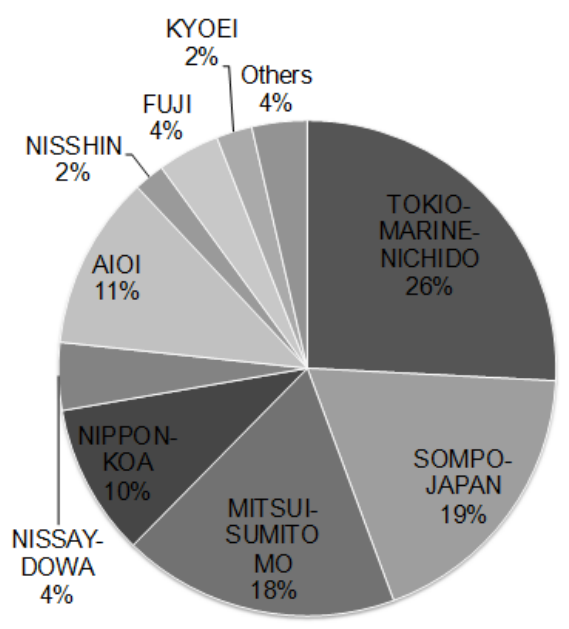

(Source) The Statistics of Japanese Non-life Insurance Business, Insurance Research Institute

\footnotetext{
${ }^{5}$ In April 2001, NIPPON-KOA General Insurance was established through a merger of NIHON Fire and Marine Insurance and KOA Fire and Marine Insurance. CHIYODA Fire and Marine Insurance and DAI-TOKIO Fire and Marine Insurance were merged together to establish AIOI Insurance. DOWA Fire and Marine Insurance and NISSAY General Insurance merged and established NISSAY-DOWA General Insurance. In October 2001, the third and fourth largest P/C insurers, MISTUI Marine and Fire Insurance and SUMITOMO Marine and Fire Insurance, respectively, also merged to establish MITSUI-SUMITOMO Marine and Fire Insurance.
} 
In the last decade, the Japanese nonlife market experienced (1) epoch-making changes in the regulatory environment, (2) drastic market saturation, and (3) a massive wave of consolidations. How do these big changes affect each other? In fact, the first two changes (regulatory environment and market saturation) are exogenous for individual insurers, but the last change is endogenous for them. Hence, we can focus on how these exogenous factors have motivated the insurers' consolidation drive. Unfortunately, because of significant data availability constraints, it would be no simple task to empirically establish whether these changes have a causal relationship. At best, we can theoretically discuss how these two exogenous changes have steered the insurers toward consolidation. In this study, we describe these cause-and-effect relationships by applying the traditional Salent el al. (1983) model.

\section{The Model and Its Implications ${ }^{6}$}

Incentive for Consolidation with No Premium Regulation Suppose that there are $n \geq 3$ insurers in the insurance market. All insurers before the merger have the same marginal cost, denoted by $c \geq 0$. The following two-stage game is developed. In the first stage, each insurer chooses whether to merge with the firm's rival(s). The number of merged insurers is represented by

(where $2 \leq m \leq n-1)$. Thus, $n-m+1$ insurers remain after the merger. The merged insurer's marginal cost after the merger is denoted by $c_{M}$, assuming $0 \leq c_{M} \leq C$. This assumption means that a merger can lower the marginal cost thanks to economies of scale and/or scope. In contrast, the merger may induce fiercer competition because it decreases the number of insurers in the insurance market. Thus, the effect of a merger is ambiguous.

In the second stage, all remaining insurers compete with their quantities (i.e., Cournot competition) ${ }^{7}$. The demand function is assumed to be linear as follows ${ }^{8}$.

\footnotetext{
${ }^{6}$ This model closely follows Salent et al. (1983). However, Salant et al. (1983) did not consider merger effects such as cost reduction. Perry and Porter (1985) introduced the difference between merged and non-merged firms in terms of capital stocks. In addition, their cost function contains the amount of capital stocks. Okura (2006) considered the merger effect in terms of the degree of risk aversion.

7 In the real world, both life and non-life insurers are limited by their capacity. For example, a number of underwriters or agents restrict their maximum sales. Thus, we may have to establish the game in which all insurers simultaneously choose their own capacity and, after these capacity levels are made public, premium rates. However, according to Kreps and Scheinkman (1983), this two-stage game generates a unique equilibrium. This is the same as a Cournot outcome, and the capacities correspond to Cournot quantities. Thus, the outcome in our model is the same as this two-stage game.

8 This insurance demand function implicitly contains the risk types of individuals. The reservation insurance premium of each individual depends on his/her accident probability. The more the accident probability, the higher the reservation insurance premium is. Thus, when all individuals are lined from the lowest to the highest
} 


$$
p=a-Q
$$

where $a>c ; p$ and $Q$ represent the premium and quantities, respectively. The profit function of non-merged insurer can be written as follows:

$$
\Pi_{i}=(p-c) q_{i}
$$

where $q_{i}$ represents quantities sold by insurer $i$. In contrast, the profit function of the merged insurer can be written as

$$
\Pi_{M}=\left(p-c_{M}\right) q_{M}
$$

where the values with subscript $M$ indicate the merged insurer's.

This game can be solved by backward induction. Therefore, let us first consider the second stage. The second stage has two possible cases: non-merger and merger. It is easy to derive the equilibrium values for non-merger, because this is nothing but Cournot competition among insurers whose marginal costs are equal. The equilibrium quantities and profits are

$$
\begin{aligned}
q_{i}^{*} & =\frac{a-c}{n+1} \\
\Pi_{i}^{*} & =\left(\frac{a-c}{n+1}\right)^{2}
\end{aligned}
$$

where the superscript " $* "$ indicates this is the equilibrium value. Thus, the total profit of $m$ insurers is

$$
m \Pi_{i}^{*}=m\left(\frac{a-c}{n+1}\right)^{2}
$$

On the other hand, in the case of a merger, there are two types of insurers: a single merged insurer whose marginal cost is $c_{M}$ and $n-m$ non-merged insurers whose marginal costs are $c$. Thus, this represents Cournot competition with $n-m+1$ insurers whose marginal costs are not equal. The equilibrium quantities and profits of the merged insurer are $^{9}$

accident probability, we find that the demand function slopes to the right.

${ }^{9}$ The equilibrium quantities and profits of non-merged insurers are omitted because these values are not relevant to subsequent discussions. 


$$
\begin{aligned}
q_{M}^{*} & =\frac{a-(n-m+1) c_{M}+(n-m) c}{n-m+2} \\
\Pi_{M}^{*} & =\left\{\frac{a-(n-m+1) c_{M}+(n-m) c}{n-m+2}\right\}^{2}
\end{aligned}
$$

Next, let us consider the first stage. An insurer would naturally opt for merger only if it results in more profits. Thus, a condition that is appropriate for a merger can be represented as

$$
f \equiv \Pi_{M}^{*}-m \Pi_{i}^{*}=\left\{\frac{a-(n-m+1) c_{M}+(n-m) c}{n-m+2}\right\}^{2}-m\left(\frac{a-c}{n+1}\right)^{2} \geq 0
$$

First, we check the case of $c=c_{M}$, which implies the merger has no cost reduction effect. Substituting $c=c_{M}$ into equation (9), we get $^{10}$

$$
f=\left(\frac{1}{n-m+2}\right)^{2}-m\left(\frac{1}{n+1}\right)^{2} \geq 0 \Rightarrow(n+1)^{2}-m(n-m+2)^{2} \geq 0
$$

Whether equation (10) is satisfied is ambiguous, but it is not satisfied in most realistic cases. For example, in the case of $n=30, m$ must be higher than about to satisfy equation (10), a situation that is difficult to imagine in the real world. Thus, we can regard $c>C_{M}$ as the de facto necessary condition for merger. Therefore, cases in which equation (10) is satisfied are eliminated from subsequent discussions. In other words, we assume that the following condition is always satisfied $^{11}$.

$$
(n+1)^{2}-m(n-m+2)^{2}<0
$$

We need to examine the characteristics of equation (9) in detail to fully understand the merger condition. Because function $f$ is a quadratic function of , we define $f \equiv f(a)$. To determine the form of function $f(a)$, we compute its first-order condition as follows:

\footnotetext{
${ }^{10}$ Equation (10) was originally derived by Salant et al. (1983).

${ }^{11}$ Equation (11) can be rewritten as $m<n-(1 / 2)(\sqrt{4 n+5}-3)$.
} 


$$
\frac{\partial f(a)}{\partial a}=-\frac{2(a-c) m}{(n+1)^{2}}+\frac{2\left\{a+c(n-m)-(n-m+1) c_{M}\right\}}{(n-m+2)^{2}}=0
$$

We denote the maximum point of $f(a)$ as $\bar{a}$. From equation (12), $\bar{a}$ can be derived as ${ }^{12}$

$$
\bar{a}=\frac{\left\{m^{3}+n(n+1)^{2}-2 m^{2}(n+2)+m(2 n+3)\right\} c-(n-m+1)(n+1)^{2} c_{M}}{(m-1)\left\{m^{2}+(n+1)^{2}-m(2 n+3)\right\}}
$$

Furthermore, equation $f(a)$ can be solved as follows:

$$
a=\bar{a} \pm \frac{(n+1)(n-m+1)(n-m+2)\left(c-c_{M}\right) \sqrt{m}}{(m-1)\left\{m^{2}+(n+1)^{2}-m(2 n+3)\right\}}
$$

Hereafter, the negative values of second term in the right-hand side of equation (14) represent and the positive values, . Thus, $a_{1} \leq \bar{a} \leq a_{2}$. Before deriving the main result, the following lemma is confirmed.

Lemma: $a_{1} \leq c \leq \bar{a}$ and $a_{2} \geq c$

Proof: It is easy to verify $a_{1} \leq c$ because

$$
c-a_{1}=\frac{(n+1)\left(c-c_{M}\right)}{n+1+\sqrt{m}(n-m+2)} \geq 0
$$

Next, examine $c \leq \bar{a}$. The difference can be calculated as follows:

$$
\bar{a}-c=\frac{(n-m+1)(n+1)^{2}\left(c-c_{M}\right)}{(m-1)\left\{m^{2}+(n+1)^{2}-m(2 n+3)\right\}}
$$

12 The second-order condition is always satisfied because

$$
\frac{\partial^{2} f(a)}{\partial a^{2}}=\frac{\left[2\left\{(n+1)^{2}-m(n-m+2)^{2}\right\}\right]}{\left\{(n+1)^{2}(n-m+2)^{2}\right\}}<0
$$


Thus, to confirm $c \leq \bar{a}$, we need to prove $m^{2}+(n+1)^{2}-m(2 n+3)>0$. Suppose $g(m, n) \equiv m^{2}+(n+1)^{2}-m(2 n+3)$. Then, it is sufficient to prove $g(m, n)>0$ even in the case of minimum $g(m, n)$. Differentiating $g(m, n)$ with respect to $n$,

$$
\frac{\partial g(m, n)}{\partial n}=2(n-m)+2>0
$$

>From equation (17), minimum translates to minimum $g(m, n)$. Thus, $n=3$. Similarly, differentiating $g(m, n)$ with respect to ,

$$
\frac{\partial g(m, n)}{\partial m}=-2(n-m)-3<0
$$

$>$ From equation (18), maximum translates to minimum $g(m, n)$. Thus, $m=2$ because $n=3$. Substituting $n=3$ and $m=2$ into $g(m, n), g(3,2)=2$. Thus, $g(m, n)>0$ is always satisfied, which confirms $c \leq \bar{a}$. Lastly, $a_{2} \geq c$ is easy to confirm because $\bar{a} \leq a_{2}$ and $c \leq \bar{a}$.

>From the lemma, the form of function $f(a)$ is clarified, and following proposition can be derived.

Proposition: The condition in which a merger is realized is $c<a \leq a_{2}$.

This proposition indicates that if the value of $a$ is relatively large so that $a>a_{2}$ is satisfied, the insurers do not have an incentive to merge. This result can be explained as follows. It is easy to verify that $\Pi_{M}^{*}>\Pi_{i}^{*}$ because a merger is implemented to decrease the number of insurers and lower the average cost. However, the difference between $\Pi_{M}^{*}$ and $\Pi_{i}^{*}$ becomes smaller as $a$ grows larger. Thus, because $m$ is a constant value, $m \Pi_{M}^{*}<\Pi_{i}^{*}$ is realized when $a$ is large and the difference between $\Pi_{M}^{*}$ and $\Pi_{i}^{*}$ is small. 
In order to shed light on the meaning of the proposition, function $f(a)$ is depicted in Figure 5.

Figure 5: The Function Form

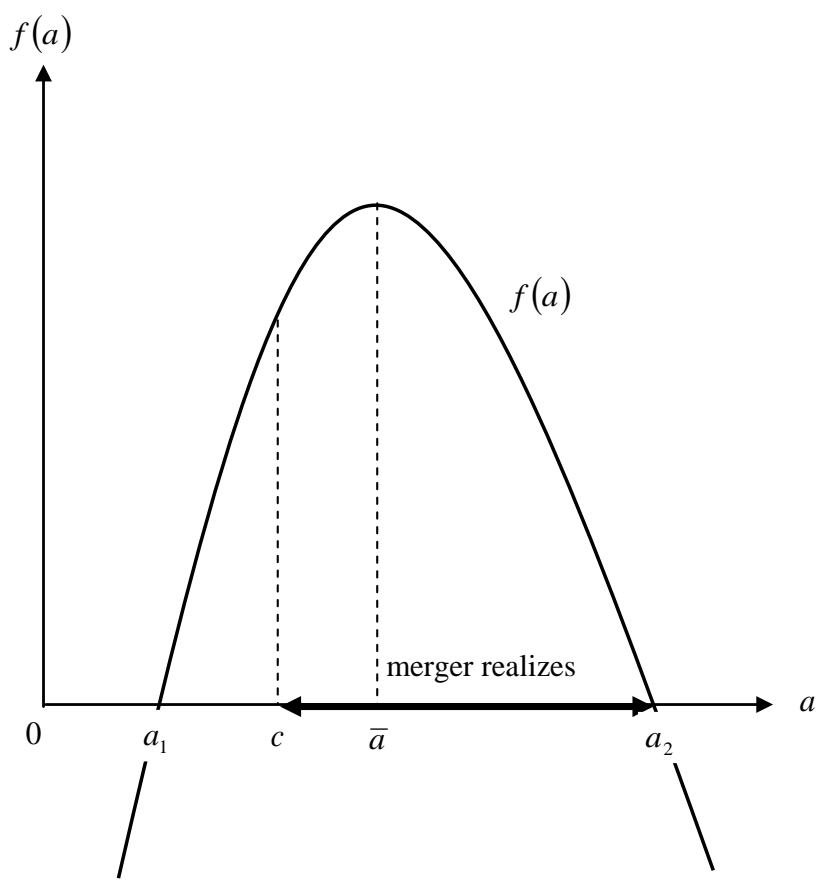

The implications of the proposition are as follows. First, a merger possibility increases in the case of a small $c_{M}$ because $a_{2}$ is larger when is smaller. This means that as the cost reduction effect becomes larger, each insurer tends to merge. This is an intuitive result. Second, smaller $a$ signals a merger possibility. This result implies that a lower demand for insurance due to saturated market conditions prompts each insurer to merge.

Incentive for Consolidation with Premium Regulation Suppose that premium rates are regulated and the regulator fixes the premium as $p=\bar{p}$. >From $p=\bar{p}$, the demand function, represented by equation (1), can be rewritten as

$$
\bar{p}=a-n \hat{q}_{i}
$$


where the hat $(\wedge)$ indicates that the value is determined under premium regulation. $>$ From equation (19), each insurer's demand before and after the merger is shown, respectively, as

$$
\begin{aligned}
\hat{q}_{i} & =\frac{a-\bar{p}}{n} \\
\hat{q}_{M} & =\frac{a-\bar{p}}{n-m+1}
\end{aligned}
$$

>From equations (20) and (21), the profits of the merged insurer before and after the merger are, respectively,

$$
\begin{aligned}
m \hat{\Pi}_{i}^{*} & =m(\bar{p}-c) \frac{a-\bar{p}}{n} \\
\hat{\Pi}_{M}^{*} & =m\left(\bar{p}-c_{M}\right) \frac{a-\bar{p}}{n-m+1}
\end{aligned}
$$

$>$ From equations (22) and (23), the condition in which the merger is realized can be represented as

$$
g \equiv \hat{\Pi}_{M}^{*}-m \hat{\Pi}_{i}^{*}=(a-\bar{p})\left\{\frac{m(n-m+1) c-(m-1)(n-m) \bar{p}-n c_{M}}{(n-m+1) n}\right\} \geq 0
$$

$>$ From $a-\bar{p} \geq 0$ and $n-m+1>0$, we find

$$
\operatorname{Sgn}[g]=\operatorname{Sgn}\left[m(n-m+1) c-(m-1)(n-m) \bar{p}-n c_{M}\right]
$$

The sign of the right-hand side of equation (25) is ambiguous. However, equation (25) becomes negative when $\bar{p}$ is relatively high. This implies that insurers do not have an incentive to merge when the regulator sets a relatively high premium. >From this result, we can derive the following proposition. 
Proposition: Premium deregulation is a necessary condition for merger incentives to occur.

In a nutshell, deregulation is needed for mergers to happen, and oversaturated insurance markets promote mergers.

To shed light on the above discussion, we will now consider the merger incentive from actual data for the period 1984 to 1995, presented in Table $1^{13}$. The insurers during the period numbered 22 , on average, and we only consider two-firm mergers. The average combined ratio from 1984 to 1995 is $\quad$ Thus, substituting $n=22, m=2$, and $\frac{c}{\bar{p}}=0.9$ into equation (25), we have

$$
\operatorname{Sgn}[g]=\operatorname{Sgn}\left[17.8 \bar{p}-22 c_{M}\right]
$$

$>$ From equation (26), the condition that satisfies $f>0$ can be written as

$$
17.8 \bar{p}-22 c_{M}>0 \rightarrow \frac{c_{M}}{\bar{p}}<\frac{17.8}{22} \approx 0.8091
$$

Equation (27) shows that merger incentives are realized only if the combined ratio increases by about $10 \%\left(\approx \frac{(90-80.91)}{90}\right)$ by a merger. However, because the minimum combined ratio during the period 1984 to 1995 is (in fiscal 1988), we conclude that no merger incentives arise before the 1996 deregulation.

\footnotetext{
${ }^{13}$ We use pre-1995 data because this discussion concerns the regulated Japanese insurance market before the drastic amendment to the Japanese insurance business law.
} 
Table1: Combined ratio and number of insurers from 1984 to 1995

\begin{tabular}{|c|c|c|}
\hline FY & Combined Ratio* & Number of Insurers ${ }^{\star *}$ \\
\hline 1984 & 90.22 & 21 \\
\hline 1985 & 90.81 & 21 \\
\hline 1986 & 88.2 & 21 \\
\hline 1987 & 85.81 & 21 \\
\hline 1988 & 84.22 & 21 \\
\hline 1989 & 85.88 & 22 \\
\hline 1990 & 89.76 & 22 \\
\hline 1991 & 99.68 & 23 \\
\hline 1992 & 95.94 & 23 \\
\hline 1993 & 94.49 & 23 \\
\hline 1994 & 89.59 & 24 \\
\hline 1995 & 88.38 & 24 \\
\hline
\end{tabular}

* Earthquake insurance and compulsory automobile liability insurance are excluded.

** Reinsurers are excluded.

(Source) The Statistics of Japanese Non-life Insurance Business, Insurance Research Institute

\section{Concluding Remarks}

This study discusses how an insurer's motivation could be affected by (1) market saturation and (2) insurance premium deregulation by applying the traditional Salent el al. (1983) model. We conclude that a loose rate regulation is a necessary condition and market saturation a sufficient condition for consolidation in the insurance industry.

However, our model is too simple to consider some special cases of real-life mergers in the insurance market-for example, a case in which $m$ insurers merge, another $l$ insurers merge, and the remaining $n-m+l$ insurers do not merge ${ }^{14}$. In this case, we need to consider, for example, (1) whether both mergers are realized simultaneously or sequentially and (2) how many insurers join in either merger. We intend to focus on this extension in a future research.

\footnotetext{
${ }^{14}$ We are indebted to one of the referees for this point.
} 


\section{Reference List}

Amel, Dean, Colleen Barnes, Fabio Panetta, and Carmelo Salleo, 2004, Consolidation and Efficiency in the Financial Sector: A Review of the International Evidence, Journal of Banking and Finance, 28, 2493-2519.

Boubakri, Narjess, Georges Dionne, and Thouraya Triki, 2008, Consolidation and Value Creation in the Insurance Industry: The Role of Governance, Journal of Banking and Finance, 32, 56-68.

Chamberlain, Sandra, and Sharon Tennyson, 1998, Capital Shocks and Merger Activity in the Property-Liability Insurance Industry, Journal of Risk and Insurance, 65 (4), 563-595.

Cummins, David, Sharon Tennyson, and Mary Weiss, 1999, Consolidation and Efficiency in the US Life Insurance Industry, Journal of Banking and Finance, 23, 325-357.

Cummins, David, and Xiaoying Xie, 2008, Mergers and Acquisitions in the US Property-Liability Insurance Industry: Productivity and Efficiency Effects, Journal of Banking \& Finance, 32 (1), 30-55.

Cummins, David, and Mary Weiss, 2004, Consolidation in the European Insurance Industry: Do Mergers and Acquisitions Create Value for Shareholders? Working Paper, Wharton Financial Institutions Center.

Kreps, David M., and José Scheinkman, 1983, Quantity Precommitment and Bertrand Competition Yield Cournot Outcomes, Bell Journal of Economics, 14 (2), 326-337.

Okura, Mahito, 2006, Welfare Effect of Firm Size in Insurance Market, Insurance Journal, 57, 113-124.

Perry, Martin K., and Robert H. Porter, 1985, Oligopoly and the Incentive for Horizontal Merger, American Economic Review, 75 (1), 219-227.

Roll, Richard, 1986, The Hubris Hypothesis of Corporate Takeovers, Journal of Business, 59, 197-216.

Salant, Stephan W., Sheldon Switzer, and Robert J. Reynolds, 1983, Losses from Horizontal Merger: The Effects of an Exogenous Change in Industry Structure on Cournot-Nash Equilibrium, Quarterly Journal of Economics, 98 (2), 185-199. 